\title{
An Application of Project-Based Learning on the Development of Young Local Tour Guides on Tai Phuan's Culture and Tourist Attractions in Sisatchanalai District, Sukhothai Province
}

\author{
Sakon Kerdpol ${ }^{1}$ \\ ${ }^{1}$ Faculty of Humanities and Social Sciences, Pibulsongkram Rajabhat University, Phitsanulok, Thailand \\ Correspondence: Sakon Kerdpol, Faculty of Humanities and Social Sciences, Pibulsongkram Rajabhat \\ University, Phitsanulok, Thailand. E-mail: niceguy2498@yahoo.com
}

Received: August 25, 2015 Accepted: December 10, 2015 Online Published: December 11, 2015

doi:10.5539/elt.v9n1p133 URL: http://dx.doi.org/10.5539/elt.v9n1p133

\begin{abstract}
This paper presents an investigation of a research entitled, "An Application of Project-based Learning on the Development of Young Local Tour Guides on Tai Phuan's Culture and Tourist Attractions in Sisatchanalai District, Sukhothai Province. It was intended to develop young local tour guides on Tai Phuan's culture and tourist attractions in Sisatchanalai, Sukhothai Province. The study explored the improvement in students' communicative ability and examined to what extent the students revealed both positive and negative attitudes towards project-based learning. The study also aimed to develop a set of recommendations for future practice in project-based learning in Thai educational institutions. The research was conducted in classroom of 50 grade 10 students with purposive sampling of Muangchalieng School in Sisatchanalai, Sukhothai Province.

The questionnaire aimed to evaluate the students' satisfaction of the methodology called project-based learning in terms of their attitude in English language development and the practice of young local tour guides. A focus-group interview with each group provided in-depth information regarding their learning and provided ideas for a set of recommendations for future practice. It is anticipated that the information gained from this study will benefit both the teachers in their choices of suitable methodologies and students' outcomes with the respect to improved competency in their skills in English and increased confidence in project-based learning in small groups.
\end{abstract}

Keywords: project-based learning, development, young local tour guide, Tai Phuan's culture, tourist attractions, Sisatchanalai

\section{Introduction}

Sisatchanalai traditionally was named Chalieng according to Lanna document and from Yonok Legend which stated that when King Sirichai along with his family left Yonok from Mon and Tai Yai armies through Chalieng and established in Traitrung in 1004 BE and according to Sung Dynasty in China (960-1127 BE) had mentioned about Chernglieng which is Chalieng in present. Till the reign of King Ramkhamhang the Great, Chalieng had been moved to the northern part in a plain called Ancient Sisatchanalai. For the Tai Phuan who migrated from Chieng khwang, Luang Phrabang, during King Rama III of Chakri Dynasty, to live in Hadsio, Hadsung, Barn Mai of Sisatchanalai (Phothisunthorn, 1986).

Though time passed, Tai Phuan people still inherited culture, language, tradition, festivals and ways of life not only in the forms of cloth weaving, but black smith and ordination on elephant during April, Kampha, Songkran Festival for Elderly people (the event to pay homage and pour water to elderly people asking them to forget and forgive the younger generation's previous mischievous acts and bless the younger ones during traditional New Year in April).

Beside the Tai Phuan ancestors who settled down in a plain where Yom River flows through the town resulting in the prosperity in agriculture, some areas are mountainous, forestry, natural parks like Pa Kha National Park where the well known and beautiful waterfalls known as Tad Duen and Tad Dao are located. In addition, Sisatchanalai World Historical Park, Thuriang Kilns at Kohnoi were found here during Sukhothai became the first capital of Thailand. These factors aforementioned create cultural tourism and eco tourism which bring incomes for local people (Thiengtham, 2001). 
Society not only has been changed through globalization but also national culture and ways of lives. It is very fortunate that Thailand has been located in a Golden land which is likely to have less frequent natural disasters comparing to the same regional areas or other Asian areas. Thailand is not only rich in natural capital but also cultural capital resulting in the in-coming incomes to develop the country. How to preserve and sustain tourism affecting the well beings of the Thai citizens, educational institutes play important role for the society, Pibulsongkram Rajabhat University is no exception to provide academic assistance to the society as it is the university for local development. The university role is to strengthen academic affairs, promote, conserve arts and culture, natural resources and environment; therefore, the university has to research and develop for the sustainable community and society (Pibulsongkram Rajabhat University, 2014).

It is according to the policy of Thailand especially educational policy supporting English instruction in schools enabling students to communicate in English locally and internationally more appropriately. Therefore, the government has designated English into the learning content for basic education (Department of Academic, 2003). English has been promoted to be used in local tourism more concretely and it is a by-product for tourism.

Tourism has produced the most incomes for Thailand as you can see the report from Bangkok Post saying that more than 22 million tourists visited Thailand last year, up nearly $16 \%$ year-on-year, setting a new record for the kingdom. Moreover, the Ministry of Tourism and Sports said 22.3 foreigners visited Thailand in 2012, with the Chinese (2.7 millions) just topping Malaysians ( 2.5 million), followed by Russians (1.3 million), Japanese (1.3 million), Koreans (1.1 million), British $(870,164)$ and Germans $(681,566)$ (Thailand tourism: New record set in 2012/ Bangkok Post).

The office of Tourism Development, Ministry of Tourism and Sports mentioned about the outcome from Community Based Tourism is a two-bladed-sword; that is, if the preparation within the community is well equipped and the proper tourists are organized, these can build up the immunity for the community and create satisfaction for the tourists. Tourism is the developing tool that can be sustainable in three areas as follows: society and culture, environment, and economy (Office of Tourism: 2007).

The researcher believes that using cultural tourism learning through project-based learning in grade 10 students in the forms of learning vocabulary and tourism content including history of Tai Phuan, tourist attractions, culture, traditions, festivals, accommodations, local foods, souvenirs of Tai Phuan people in Sisatchanalai will enable students to use English as a young local tour guide and apply this in their real life more efficiently and also to instill the love and caring in their tourist attractions, cultures and tradition and finally they can get the learning media for their future use.

This research presents a study of "An Application of Project-based Learning on the Development of Young Local Tour Guides on Tai Phuan's Culture and Tourist Attractions in Sisatchanalai District, Sukhothai Province by using project-based learning researched by Thomas (2000) on the principal features of PBL which were consistent with many educators who studied and implemented this teaching method (Curtis, 2002, Solomon, 2003; Helle, Tynjala, \& Olkinuora, 2006). Features of PBL include: (a) complex explorations over a period of time; (b) a student-centered learning activity whereby students plan, complete and present the task; (c) challenging questions, problems or topics of student interest which become the center of the project and the learning process; (d) the de-emphasis of teacher-directed activities; (e) frequent feedback from peers and facilitators; (f) hands-on activities and the use of authentic resources and technologies; (g) a cooperative learning environment rather than a competitive one; (h) the use of a variety of skills such as social skills and management skills.

Project-based learning is not only for learning within L1 classrooms, it can be applied in the ESL Classroom because it builds on the principles that when students are cooperatively engaged in a motivating project, task or experience, and then reflective or mindful of the results and how to further apply them, they are actively participating in the learning (and self teaching) process. Experiential learning especially in project based learning is more than field trips to museums, ponds, and post offices-this is a method of learning with practices that can successfully be applied in the ESL classroom (Hu, 2006).

To be effective learners ones must (1) perceive information, (2) reflect on how it will impact some aspect of one's life, (3) compare how it fits our own experiences, and (4) think about how this information offers new ways for us to act. Learning requires more than seeing, hearing, moving, or touching to learn. We integrate what we sense and think with what we feel and how we behave.

The research manuscript provides a context for the study by exploring the relevant literature and describes the methodology used in collecting and analyzing data as well as the ethical principles adopted to guide this process. The findings of the study are discussed and illustrated drawing upon the narrative data of the methodology used. 
Finally, the conclusion summarizes the findings and suggests some implications that could inform further studies as well as approaches to the development of learning and teaching techniques for instruction in English as a foreign language.

\section{Objectives of the Study}

This chapter describes how the research was conducted so as to:

1). Develop a young local tour guide of Muangchalieng School students by using project-based learning,

2). Explore the improvement in students' communicative ability through project-based learning,

3). Examine to what extent the students have positive and negative attitudes towards project-based learning,

\section{Materials and Methods}

This study is qualitative research by using questionnaire, focus group interview and reflective journal. It was conducted in a classroom of 50 ten grade students of Muangchalieng School in Sisatchanalai, Sukhothai Province where project-based learning approach was being implemented. The reason in choosing this school because it is the biggest school in Sisatchanalai and also the majority of the students are from Tai Phuan families so they meet with the research project. The subjects were purposively sampled and placed them into 6 heterogeneous groups of eight and one group of nine. These groups consisted of students with mixed abilities from their pretest scores. The students named their own groups as follows: Infinity, Doraemon, Genius, Legend, Galaxy Tap and IPAD respectively. They were brainstorming on the topics that they would be assigned to work on their project as follows: History of Tai Phuan, Local Foods, Local Souvenirs, Accommodations, Tourist Attracts in Sisatchanalai, Festivals of Sisatchanalai. Pre test was given to students for the first week. The students were tested on vocabularies related to the topics chosen by students and gap filling how to be a local tour guide. The contents (topics chosen by students) were taught and discussed for seven weeks; week 8 and 9 , students went on the field trips to Ancient Silversmith, Ancient Goldsmith, Sisatchanalai Historical Park, Sathorn Museum and finally Pakha National Park. Finally week 10 was for the students' project presentation with power points after they have done the post test.

Data collection activities included questionnaire, reflective journal and focus group interview. Christensen and Johnson (2000) define a questionnaire as a self-report data-collection instrument that each research participant fills out as part of a research study and focus group interview is a data-collection method in which an interviewer (the researcher or someone working for the researcher) asks questions of interviewees (the research's participants). A reflective journal or dairy or field log is the recording of the thoughts, feelings, ideas and hypotheses generated by students' contact with other participants (Depoy \& Gitlin, 1998). A student questionnaire investigated 50 students' attitudes towards project-based learning approach, the students' reflective journal provided insights into the project-based learning approach and a focus group interview of 50 students provided triangulation of the findings.

The researcher developed the questionnaire, test items, and interview questions and had three experts from Pibulsongkram Rajabhat University check for the IOC. They were tried out with English Program students of Chalermkhansatree School in Phitsanulok to enable to the readjustment of the questionnaire, test items and interview questions. The questionnaire items have been adapted from Slavin (1995). The questionnaire items are comprised of 40 items: 20 items with positive attitudes and 20 with negative attitudes. The test items comprised of vocabulary matching related to the research title, and gap filling on being a tour guide. The 12 itemedinterview questions were asked and answered by focus group interviewees and they can answer either in English or Thai so students can express their thoughts more fruitfully and meaningfully. This time the interview was recorded and videotaped and then the recording scripts were transcribed into English in order to be analyzed into themes.

The questionnaire data were analyzed using the SPSS program and key categories and themes were identified. Focus group interviews and reflective journals were analyzed into categories and themes adapted from Baddeley (1992) in Cook and Finlayson (1999).

\section{Results and Discussion}

The students' post test scores of 50 ten grade students at Muang Chalieng School were much higher than the pre test scores due to the fact that they have experienced using the vocabularies during the lessons and the tour guide pattern has been practiced very often. Therefore, those led to the improvement of development. In terms of questionnaire, it was found that most students had positive attitudes; however, there were only a few students who had negative attitudes towards project-based learning approach. 
Categories and themes found in focus group interviews reflective journal were put into Activities students worked on, Types of learning and Skills acquired. The themes under Activities Students worked on are Discussing of ideas, Preparing oneself, Sharing ideas, Arguing and compromising, Offering help, Questioning and Seeking clarification, Searching for information, Judging, Praising and encouraging, Building confidence, Becoming a leader and/or followers, and Learning to work together. The themes under Types of learning are Recording existing knowledge, Arranging information, Transferring knowledge, Democratizing their thinking and information, Being part of a team and caring for others, Making connection with prior learning, Applying knowledge to a new situation, Accepting others' ideas, Rewarding others, Consolidating information and applying prior knowledge to a new situation, Perceiving the social roles and Making connection with a group. The themes under Skills acquired are An understanding of new information, Being responsible for the topic assigned, Reordering what they know, Turn taking and Accepting others, An understanding of socialization, Negotiating and expressing doubts, Sharing ideas and listening to others, Selecting the information, Supporting others, Expressing ideas, opinions frequently, Accepting the roles of self and others and Sharing responsibility.

The first set of data collection addressed in this chapter was administered by using the questionnaire which was composed of 40 statements investigating both positive and negative attitudes towards project-based learning in the development of young local guides on Tai Phuan's culture and tourist attractions in Sisatchanalai, Sukhothai Province. The questionnaire was divided into three parts. Part I: Background information on participants such as gender, age and how long the participants have studied English. Part II consisted of 40 items measuring both positive and negative attitudes using Likert's five rating scales (Johnson \& Christensen, 2000). After collecting the questionnaires from the participants, the researcher double checked that all the questionnaires were returned and that every item had been checked in order to ensure the reliability of each item (Cohen, Manion, \& Morrison, 2000). For the confidentiality of the 50 participants, names have not been identified. Instead, each questionnaire has been given a code number from participant 1 to participant 50 . The data were analyzed using SPSS.

\subsection{Background Information on the Participants}

The six groups of 50 ten grade students studying Science section at Muangchalieng School, Sisatachanalai, Sukhothai Province purposively joined in the study. A profile of these participants is provided in Table 1 and includes details of gender, age and years of studying English.

Table 1. Participant Profiles from the questionnaire

\begin{tabular}{lllllllll}
\hline Gender & freq & $\%$ & Age & freq & $\%$ & Years of Eng & freq & $\%$ \\
\hline $\mathrm{M}$ & 15 & 30 & $13-14 \mathrm{yrs}$ & - & & $3-5$ & 1 & 2 \\
& & & & & & $6-8$ & 5 & 10 \\
$\mathrm{~F}$ & 35 & 70 & $15-16 \mathrm{yrs}$ & 50 & 100 & $9-11$ & 42 & 84 \\
& & & & & & Others 13 & 2 & 4 \\
Total & 50 & 100 & & 50 & 100 & & 50 & 100 \\
\hline
\end{tabular}

Description and Discussion: This profile shows that there were only fifteen male students (30\%) enrolled in the Science section program. Female students represented a greater number in the cohort $(70 \%)$. The ages were classified into two groups: the first category was none but all of them (100\%) were 15-16 years of age. The number of years studying English mostly (42 students $=84 \%$ ) falls on 9-11 years which mean the students started studying English when they were in a primary school, whereas, only one student had 3-5 years of English (2\%) studied English late in a secondary school. Only two students (4\%) studied English from kindergarten.

\subsection{Items of the Questionnaire}

There were 40 items in the questionnaire: 20 items were positive statements and another 20 items were negative ones. These were mixed in order. Participants were asked to report whether they felt positive or negative attitudes to the project-based learning. The positive statements were identified by $\mathrm{B}$ and negative ones were identified by R B. The positive statements were given numerical values from five to one (strongly agree, agree, not sure, disagree and strongly disagree), and one to five for the negative statements. The 40 items (both positive and negative statements) and their respective scores were then analyzed to find the mean in each case. It can be seen that all 19 positive items of the questionnaire were at the "Agree" and "Strongly agree" level and only one item was at Not sure. All 20 negative attitude items of the questionnaire were at the "Agree" and "Strongly 
agree" level. As a result, it was evident that the majority of participants felt positive in their attitudes towards project-based learning approach. Students were asked to respond on a Likert's Scale indicating the extent to which they agreed or disagreed with a statement. For example:

\begin{tabular}{llllll}
\hline & Strongly & Agree & Not \\
sure & Dis- & Strongly \\
Items in the questionnaire & Agree & 4 & 3 & 2 & 1 \\
\hline
\end{tabular}

1. Working in small group with Project-based Learning helps me learn English as a local guide.

2. I find it hard to talk in English as a local guide in a small group.

8. Working in s small group helps make me proud of myself as being a helpful participant.

22. Working in a small group hinders my learning.

\subsection{Results of Comparison on Questionnaire}

Table 2 provides a detailed summary of the students' responses to the questionnaire items.

Notes: Levels of attitudes were divided into 5 categories (Best \& Kahn, 1986) as follows:

With the mean from $4.50-5.00=$ Strongly agree

With the mean from $3.50-4.49=$ Agree

With the mean from $2.50-3.49=$ Not sure

With the mean from $1.50-2.49=$ Disagree

With the mean from $1.00-1.49=$ Strongly disagree

Table 2. Showing Mean, Standard Deviation and Levels of positive and negative attitudes

\begin{tabular}{|c|c|c|c|}
\hline Items in the questionnaire & & S.D. & $\begin{array}{l}\text { Levels of positive and } \\
\text { negative attitudes }\end{array}$ \\
\hline $\begin{array}{l}\text { B1 Working in a small group with Project -based Learning helps me } \\
\text { learn my English as a local guide. }\end{array}$ & 4.32 & .819 & Agree \\
\hline $\begin{array}{l}\text { R_B1 I find it hard to talk in English as a local guide in a small } \\
\text { group. }\end{array}$ & 4.10 & .789 & Agree \\
\hline $\begin{array}{l}\text { B2 Working in a small group helps me learn English better than other } \\
\text { methods such as lecturing from teacher. }\end{array}$ & 4.14 & .783 & Agree \\
\hline $\begin{array}{l}\text { B3 Working in a small group motivates me to learn more about a } \\
\text { local guide. }\end{array}$ & 4.00 & .969 & Agree \\
\hline $\begin{array}{l}\text { B4 Working in a small group provides me with good studying } \\
\text { strategies. }\end{array}$ & 4.14 & .833 & Agree \\
\hline $\begin{array}{l}\text { R_B } 2 \text { Working in a small group makes someone dominant in the } \\
\text { group especially when discussing. }\end{array}$ & 4.50 & .505 & Strongly agree \\
\hline $\begin{array}{l}\text { B5 Working in a small group helps me understand individual } \\
\text { differences. }\end{array}$ & 4.50 & .678 & Strongly agree \\
\hline $\begin{array}{l}\text { B6 Working in a small group helps make me proud of myself as } \\
\text { being a helpful participant. }\end{array}$ & 4.42 & .785 & Agree \\
\hline R_B3 I am easily influenced by friends in working in a small group. & 4.38 & .635 & Agree \\
\hline R_B4 Working in a small group occupies most of my time. & 4.68 & .471 & Strongly agree \\
\hline
\end{tabular}


B7 Working in a small group helps me adjust myself.

R_B5 Working in a small group makes me nervous.

B8 Working in a small group provides me with a positive attitude towards the teacher and my colleagues.

B 9 Working in a small group creates individual accountability.

R_B6 I really worry about what others think of me especially when working in a small group.

B10 Working in a small group creates willingness to compromise and cooperate.

R_B7 Working in a small group slow down my learning especially being a local guide.

B11 Working in a small group provides me more self confidence.

B12 Working in a small group helps create companionship.

R_B8 Working in a small group makes me dependent.

B13 I work best in a small group.

R_B 9 Working in a small group hinders my learning.

B14 I am ambitious to speak out as a local tour guide in a small group.

R_B10 I am often afraid that I may look ridiculous or make a fool of myself in working in a small group.

B15 Working in a small group provides me with a good learning style.

R_B11 Working in a small group creates interpersonal problems.

R_B12 I feel embarrassed when making a mistake especially during practicing as a tour guide in a small group.

R_B13 I lack self-confidence when working in a small group.

R_B14 I sometimes have difficulty controlling my temper when practicing as a tour guide in a small group.

B16 Working in a small group creates a nice learning atmosphere.

R_B15 Working in a small group wastes my time.

R_B16 I learn better if I study by myself.

B 17 Working in a small group teaches us social roles.

R_B17 I feel shy when working in a small group.

R_B18 I get upset when someone in a small group does not help work in a group.

B18 I feel proud to volunteer to present a small group work.

B19 I feel very happy when friends applause after presentation.

R_B19. I feel reluctant to volunteer first when working in a small group

B20 Working in a small group makes me more eager to speak English with foreigners.

R_B20 I feel discourage when I cannot do what others can when working in a small group.

Mean all

$\begin{array}{lll}4.22 & .910 & \text { Agree } \\ 4.12 & .872 & \text { Agree } \\ 4.40 & .833 & \text { Agree }\end{array}$

$4.50 \quad .647$ Strongly agree

4.44 .705 Agree

4.42 .835 Agree

$4.28 \quad .730 \quad$ Agree

$3.88 \quad .773$ Agree

4.48 .886 Agree

$3.98 \quad .769$ Agree

3.16 .889 Not sure

4.08 .778 Agree

3.72 .701 Agree

4.40 .639 Agree

$4.20 \quad .857 \quad$ Agree

4.48 .646 Agree

4.12 .689 Agree

4.32 .713 Agree

4.40 .700 Agree

$4.60 \quad 571 \quad$ Strongly agree

$4.68 \quad 513$ Strongly agree

$4.70 \quad .544 \quad$ Strongly agree

4.28 .858 Agree

4.40 .639 Agree

4.24 .797 Agree

$4.30 \quad 886 \quad$ Agree

4.46 .676 Agree

3.89 .937 Agree

4.02 .714 Agree

$4.58 \quad 609$ Strongly agree

$4.28 \quad .04 \quad$ Agree

Description and Discussion: The data show that the positive attitudes were 20 items (50\%) and there were only three strongly agree as follows: on item B5; that is, working in a small group helps me understand individual 
differences, item B9; that is working in a small group creates individual accountability, and item B16; that is, working in a small group creates a nice learning atmosphere. However, there was only one positive attitude falls on Not sure on item B13; that is, I work best in a small group. The rest of positive attitudes were agree. On the contrary, there were four out of 20 items of negative attitudes were on strongly agree on the following items: item R_B4; that is, working in a small group occupies most of my time, item R_B15; that is, working in a small group wastes my time, item R_B16; that is, I learn better if I study by myself and item R_B20; that is, I feel discourage when I cannot do what others can when working in a small group. The rest of negative attitudes were agrees. Comparing these two attitudes, the positive response is still a little outweighed which is consistent with similar research conducted by Ahuja (1995), Brancov (1995), Rondinaro (2004), Sirichaisin (2006), Tintechphon, (2007), Doi (2008), Suktong and Yothakamme (2009), Simpson (2011). It can be seen that from the information provided previously that grade ten students may have both positive and negative attitudes towards the methodology used in the lessons and it is natural in terms of English language teaching and learning.

\subsection{Thematic Analysis of Interviews and Reflective Journals}

The second method of analysis dealt with the interview. The interview used for this study was a focus group interview (Cohen, Manion, \& Morrison, 2000) which helped with the triangulation of the study. Fifty participants were invited to be interviewed and divided into 6 groups of eight and nine. They were given a number and the researcher used their nicknames for the analysis. All the interviews conducted were taped and video recorded for later analysis. The data gathered were transcribed and translated since some questions allowed answering in Thai. The data of focus group interview and reflective journals were categorized into themes adapted from Baddeley (1992, in Cook \& Finlayson, 1999).

\section{Conclusion}

This study examines the efficacy of project-based learning approach in developing young local tour guides on Tai Phuan's Culture and Tourist Attractions in Sisatchanalai District, Sukhothai Province. This research has helped pave the way for teachers in Thailand to identify better pedagogical approaches for students learning English as a foreign language. Project-based learning approach, the focus of this research, is one of such methodology.

This study sought to develop a young local tour guide of Muangchalieng School students by using project-based learning approach. It also sought to explore the improvement in students' communicative ability through project-based learning and to examine the extent to which the students demonstrated positive or negative attitudes towards project-based learning approach. It is hoped the findings will be applied and implemented by language teachers from various levels of institutions to improve student language learning outcomes and simultaneously provide benefits for Thailand's future progress and development as a whole.

\section{Achievement of the Aims of the Research}

It is submitted that the present study has been successful in defining an effective methodology for teaching the speaking of English as a foreign language (EFL). In doing this, a number of specific aims have been addressed and the findings, with respect to these, are reviewed and summarized below.

The first objective sought to develop a young local tour guide of Muangchalieng School students by using project-based learning approach. The findings revealed that all of the students post test scores were much improved as consistent with Johnson and Johnson and Holubec (1993), Sirichaisin (2006), Tintechphon, (2007), Suktong and Yothakamme (2009).

The second objective sought to explore the degree of improvement in students' communicative ability through project-based learning approach. As a whole, most students enjoyed working in a small group and the findings were evident that the students improved their speaking proficiency through their small group interactions.

The third objective sought to examine to what extent the students have positive and negative attitudes towards project-based learning approach. The study indicated that most students expressed a positive attitude towards project-based learning approach. It showed that all 20 positive statements that students responded to in the questionnaire were rated from much to most and the mean all was also rated much. In addition, from the 12 item focus group interviews, it was evident that they all enjoyed working in a small group. However, there were only a small number of participants who felt negative towards project-based learning approach about the teacher, their friends, topic content and learning atmosphere.

In conclusion, this study has achieved the objective stated. The findings support all the research questions. The findings also recommended that language teachers from secondary institutions that can find this approach more enjoyable, fruitful, meaningful and practical for their students in learning English. 
There were some limitations with doing this project. The first limitation was due to the constraint of time spent in the afternoon after lunch which led to the sleepy of participants. In addition, the project could not be conducted continuously due to the school routine schedule such as sports day, mid-term examination and some ad hoc mission of the school, moreover, the research was also the Dean of Humanities and Social Sciences so when there were some university mission to be fulfilled, he had to function the mission which caused the discontinuity for the project and also it affected the continuity of students' learning as expressed by students during the focus group interview and from the reflective journal of students. Next it was due to financial constraints, the study could not be conducted in many high schools in Sisatchanalai District though there are more high schools there; however, there are the majority of students who are from Tai Phuan families study here.

Further studies might focus on the outcomes possible with extended use of project-based learning approach. The approach might also be extended to include reading, writing and also with other fields of study as social studies, biology, environment, and history as mentioned by the students during the focus group interview. Moreover, this study should be conducted at other levels of schooling such as primary, vocational and tertiary education.

In conclusion, this study has achieved its aims and its findings indicate that in order to change form a traditional didactic teaching approach which has been passed on from generation to generation to an interactive-student centered one, such as project-based learning, teachers will need considerable profession development opportunities provided for them. Not only do the teachers need to prepare content more extensively but the learners also need to develop proficiency in group interaction including resolution of conflict and asserting one's point of view. The results are sufficient, however, to suggest that this approach has the potential to improve learner performance in learning English which, in turn, could represent long term benefits for Thailand's future progress and development.

\section{Acknowledgements}

This research has been funded by National Research Council of Thailand.

\section{References}

Ahuja, A. (1995). The Effect of a cooperative learning instructional Strategy on the academic achievement, attitude toward science class and process skills of middle school science students. (Doctorate Dissertation, The Ohio State University. 1994).

Best, J., \& Kahn, J. (1986). Research in Education (5th Edition). New Jersey: Prentice Hall Inc.

Brancov, T. (1995). Cooperative learning in mathematics with middle school Indian students: A focus on achievement and on-task behavior (Native Americans) (Doctorate dissertation, University of South Dakota, 1995). Dissertation Abstracts International-A 55/11, p. 3396, May 1995.

Christensen, L., \& Johnson, B. (2000). Educational Research: Quantitative and Qualitative Approaches. London: Allyn and Bacon.

Cohen, L., Manion, L., \& Morrison, K. (2000). Research Methods in Education (5th Edition). London: Routledge. http://dx.doi.org/10.4324/9780203224342

Cook, D., \& Finlayson, H. (1999). Interactive Children, Communicative Teaching ICT and Classroom Teaching. Buckingham: Open University Press.

Curtis, D. (2002). The Power of Project. Educational Leadership, 60(1), 50-53.

Department of Academic, Ministry of Education. (2003). A Study of English Instructional Condition based on Communicative Skill under the Basic Education. Research paper of Educational Research Division Order $315 / 2003$.

Depoy, E., \& Gitlin, L. (1998). Introduction to Research: Understanding and Applying Multiple Strategies (2nd Edition). New York: Mosby.

Doi, A. (2008). Let the Felt Sense Speak in English: Experiential Learning and Teaching of English as a Second Language. Retrieved May 5, 2013, from www.focusing.org/folio/vol2/No12008/17_LetTheFeltRIB.pdf

Helle, L., Tynjala, P., \& Olkinuora, E. (2006). Peer and Self-Assessment in Portuguese Engineering Education. In T. T. Roberts (Ed.), Self, Peer, and Group Assessment in E-Learning (pp. 64-84). Hershey PA: IGI.

Hu, Y. (2006). On Experiential Cultural Teaching Model in EFL College Classroom. Canadian Social Science, 2(4), 32-36.

Johnson, D. W., Johnson, R. T., \& Holubec. E. J. (1993). Circle of Learning (2nd Edition). Edina, MI: Interaction 
Book Company.

Office of Tourism. (2007). Community Based Tourism Network Handbook. Ministry of Tourism and Sports.

Pibulsongkram Rajabhat University. (2014). Information: PSRU. WWW.psru.ac.th

Phothisunthorn, W. (1986). Sisatchanalai. Bangkok: Department of Fine Arts.

Rondinaro, P. (2004). The role of interpersonal multiple intelligence on the usage of cooperative learning teaching methods. (Doctorate dissertation, Temple University, 2004). Dissertation Abstracts International-A 65/04, p. 1253.

Simpson, J. (2011). Integrating Project-Based Learning in an English Language Tourism Classroom in a Thai University. (Ph.D. thesis, 2011)

Sirichaisin, K. (2006). A Training Curriculum Development for Junior Guides on Wat Phra Sri Rattana Mahathat Vorra Mahaviharn for Patomsuksa V Students. (Master thesis, 2006)

Slavin, R. (1995). Cooperative Learning: Theory, Research and Practice (2nd Edition). Needham Heights, Massaschusetts:Allyn \& Sacon.

Solomon, G. (2003). Project-Based Learning: a Primer. Technology \& Learning, 23, 10-20.

Suktong, S., \& Yothakamme, R. (2009). The Development of a Training Curriculum on Mukkutetnoi Tam Roy Phrasatsada Su Wiangfahauytom for 3rd Level Students (Master thesis, 2009).

Thiengtham, S. (2001). Dawn of Happiness at Sukhothai. Tourism Authority of Thailand, 42(4), 42-57.

Thomas, J. W. (2000). A Review of Research on Project-based Learning. San Rafael, CA: Autodest Foundation Thailand tourism: New record set in 2012/ Bangkok Post: learning.

Tintechphon, W. (2007). Strategy in Development "Young Guides for Lamphaya Floating Market" at Banglen District, Nakhorn Pathom Province (Master thesis, 2007).

\section{Copyrights}

Copyright for this article is retained by the author(s), with first publication rights granted to the journal.

This is an open-access article distributed under the terms and conditions of the Creative Commons Attribution license (http://creativecommons.org/licenses/by/3.0/). 